\section{Conflictos de intereses: normas y conceptos}

Este comentario, junto a los documentos que analiza, está disponible en www.anuariocdh.uchile.cl

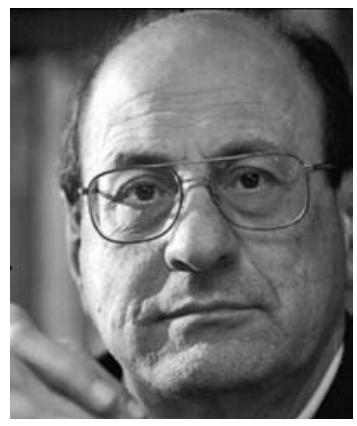

\title{
José Zalaquett
}

Abogado, Licenciado en Ciencias Jurídicas y Sociales por la Universidad de Chile, Doctor Honoris Causa por las universidades de Notre Dame y City University of New York. Es profesor de Derechos Humanos de la Facultad de Derecho de la Universidad de Chile. Participó en la Comisión de Verdad y Reconciliación y la Mesa de Diálogo. Fue elegido como miembro de la Comisión Interamericana de Derechos Humanos entre los años 2000 y 2005, siendo presidente en el período 2003 y 2004.

jzalaquet@derecho.uchile.cl

\section{RESUMEN}

En vista de los debates públicos que tuvieron lugar en Chile durante 2010 sobre conflictos de intereses que se decía afectaban a altas autoridades del Estado, este comentario intenta aclarar las normas y conceptos relativos al tema. Con ese fin, reseña el campo de probidad pública, transparencia y anticorrupción dentro del cual se sitúa el tema de los conflictos de intereses, así como las normas internacionales aplicables; sostiene que los conflictos de intereses no son hechos sino situaciones de riesgo para determinados valores públicos o colectivos que se hallan entregados a un resguardo fiduciario, público o privado; analiza distintas formas de vulneración de los valores respectivos a que tales situaciones de riesgo pueden conducir y termina revisando las principales iniciativas y leyes adoptadas en Chile sobre esta materia en las últimas dos décadas.

\section{Motivos y propósito de este comentario}

Este artículo responde a dos motivos. Primero, la comprobación del interés creciente, en Chile y en el mundo, sobre el campo de la probidad pública y la lucha contra la corrupción, unido a la necesidad de clarificar ciertos conceptos o términos, como el de conflictos de intereses, que suelen emplearse equívocamente. En segundo lugar, el hecho de que durante el año 2010, período que cubre el presente Anuario de Derechos Humanos, el debate sobre conflictos de intereses cobró especial intensidad en Chile a propósito de las situaciones de ese tipo en que podrían haber estado envueltos el Presidente de la República, Sebastián Piñera, y otras autoridades estatales ${ }^{1}$; si bien

1 Los principales debates públicos sobre las situaciones de conflictos de intereses que podrian haber afectado al Presidente Piñera y otras autoridades fueron los siguientes: (i) a fines del año 2009, durante la campaña electoral a la Presidencia de la República, se dio a publicidad en Chile el Informe Global Anticorrupción, 2009, de Transparency International que en su sección sobre Chile, cuyo texto base fue encargado al capítulo chileno de esa organización, Chile Transparente, se refería a una operación comercial de compra de acciones de LAN Airlines S.A. por parte del entonces candidato Sebastián Piñera, caracterizándola como un "incidente que significó un posible uso de información privilegiada", lo que provocó una viva polémica pública; (ii) en el período previo a su asunción del mando y durante los primeros meses 
en lo que sigue no se analizan dichos casos, a mi juicio ellos contribuyeron a hacer más patente en el país la necesidad de aclarar normas y conceptos en esta materia, lo que es la finalidad del este comentario.

A mayor abundamiento, aunque el presente Anuario está dedicado a temas de derechos humanos, el campo de la anticorrupción, si bien ostenta su propia identidad disciplinaria, normativa y práctica, tiene también vínculos específicos con el área de los derechos humanos ${ }^{2}$, además del rasgo genérico de pertenecer ambas esferas al ámbito más general de cuestiones centrales de ética pública de nuestro tiempo.

\section{Nomenclatura}

En la literatura académica y periodística sobre el tema de este artículo es posible encontrar cuatro distintas formulaciones de dicha expresión, según se utilicen cada una de sus palabras operativas (conflictos e intereses) en singular o en plural. He preferido "conflictos de intereses" porque es la expresión más frecuentemente usada en la Convención de Naciones Unidas contra la Corrupción y porque de hecho las situaciones relevantes comprenden distintos tipos de conflictos y entre variados intereses.

\section{El campo de la probidad pública y la anticorrupción}

A comienzos de la década de los años noventa, coincidiendo con el fin de la Guerra Fría y la revalorización internacional de la democracia como forma de gobierno, comenzó a emerger un nuevo campo de interés publico o, si se quiere, de ética política democrática, que se ocupa de la probidad pública, la transparencia en la gestión del Estado y el combate a la corrupción. Por "campo" me refiero a un área temática de preocupación cívica que congrega el interés de organizaciones ciudadanas y de la academia y que atrae, progresivamente, la atención del mundo político, resultando en definitiva, de todo ello, la creación de organizaciones privadas y agencias publicas, tanto a nivel nacional como regional e internacional; una creciente cobertura de los medios de comunicación masiva sobre los alcances del tema y sobre casos señeros de trasgresión de las normas y/o valores involucrados; la promulgación de leyes y la adopción de convenciones internacionales sobre la materia; y el establecimiento de fondos y programas de financiamiento de las actividades e instituciones orientadas a promover los valores públicos que tal área temática procura afirmar y proteger.

La emergencia del campo de anticorrupción formó parte central de la agenda internacional de comienzos de los años noventa llamada de good governance ${ }^{3}$, así como, en general, de la agenda de fortalecimiento de la democracia.

como presidente, Sebastián Piñera encaró diversos llamados públicos a que, cumpliendo una promesa de campaña, enajenara sus acciones en la aerolínea LAN Airlines S.A., lo que finalmente hizo. También se le formuló el requerimiento de que vendiera Chilevisión, Canal de TV abierta del que era propietario, lo que hizo, no sin tardanza. Por último, se le exigió públicamente que vendiera sus acciones en Blanco y Negro S.A., sociedad que controla al Club Deportivo Colo-Colo, el más popular del país, lo que hizo en la última semana del año 2010, aunque la oposición política objetó que el adquirente de las mismas haya sido una sociedad controlada por el Sr. Hernán Levy, consuegro del Presidente. Con anterioridad, en agosto de 2010, Gabriel Ruiz-Tagle, Subsecretario de Deportes e importante accionista de Blanco y Negro S.A., vendió sus acciones en dicha compañía, luego de un informe de la Contraloría General de la República que concluía que debía enajenarlas o bien renunciar a su cargo.

2 Sobre este punto, ver LAUZÁN, Silvana y TORO, Constanza. Anticorrupción: Actualizando los desafíos. Centro de Derechos Humanos, Facultad de Derecho, Universidad de Chile, Santiago, 2009. pp. 14 y ss. Ver también INTERNATIONAL COUNCIL ON HUMAN RIGHTS POLICYYTRANSPARENCY INTERNATIONAL, "Corruption and Human Rights: Making the Connection", ICHRP, Versoix, Suiza, 2009.

3 Sobre la emergencia de este campo a comienzos de la década de los noventa, así como sobre su vinculación con la cuestión de calidad de gobierno, ver O'BYRSE, Sarah. "The emergente of Anti-Corruption in Theory and Practice: 
Así mirado, se advierte que el campo conocido como anticorrupción surgió tres décadas más tarde que el movimiento internacional por la protección del medio ambiente y cuarenta años después del movimiento de derechos humanos, ambos actores centrales de campañas de interés público y ética política en nuestros días.

En el estado actual de la temática de probidad y transparencia, se entiende que los valores públicos que busca proteger la normativa anticorrupción son: el patrimonio público; el desarrollo económico y el orden público económico, en el sentido de buen funcionamiento de las instituciones y normas de la economía; y la fe pública y la calidad de la democracia. Conductas tales como la apropiación o uso indebido de bienes o caudales públicos, el fraude al fisco o a entidades públicas, el soborno o cohecho, la extorsión, el tráfico de influencias, el uso abusivo de información privilegiada y determinados delitos específicos relacionados con la administración de justicia, vulneran uno o más de los valores mencionados.

Con respecto a los conflictos de intereses, como se dirá con detalle más adelante, no se trata de una conducta sino de una situación o estado de cosas que implica el riesgo objetivo de que las persona involucradas Ileguen a incurrir en conductas que afectan negativamente determinados intereses públicos o colectivos ${ }^{4}$.

\section{Normativa internacional sobre anticorrupción y sobre conflictos de intereses}

Tres son las principales convenciones internacionales en esta materia: la Convención Interamericana contra la Corrupción, de 1996; la Convención para Combatir el Cohecho de Servidores Públicos Extranjeros en Transacciones Comerciales Internacionales, de la Organización para la Cooperación y el Desarrollo Económicos (OCDE), adoptada en 1997, conocida también, debido a su objetivo específico, como la convención contra el soborno internacional; y la Convención de las Naciones Unidas contra la Corrupción, de 2003. Todas ellas han sido ratificadas por Chile ${ }^{5}$.

A diferencia de la Convención de la OCDE, las otras dos son de carácter general. La Convención de las Naciones Unidas es mucho más completa que la Convención Interamericana. Ello puede deberse en buena medida al hecho de que se adoptó siete años después de esta última, habiendo mediado en el ínterin el ataque terrorista del 11 de septiembre de 2001, que dio lugar a una mayor

The Role of Epistemic Communities", artículo presentado en la reunión anual del International Studies Association sobre "Global Governance: Political Authority in Transition", Montreal, Canadá, 16 de marzo de 2001, consultado el 5 de abril de 2011 en http://www.allacademic.com/meta/p5000660_index.htm! Además, cabe recordar que Transparency International, organización internacional privada reconocida como la principal entidad que ha impulsado esta temática mundialmente, fue creada en 1993.

4 Mención especial merece el delito de enriquecimiento ilícito. En la Convención Interamericana Contra la Corrupción, el artículo IX, primer inciso, establece: "Con sujeción a su Constitución y a los principios fundamentales de su ordenamiento jurídico, los Estados Partes que aún no lo hayan hecho adoptaran las medidas necesarias para tipificar en su legislación como delito, el incremento del patrimonio de un funcionario público con significativo exceso respecto de sus ingresos legítimos durante el ejercicio de sus funciones y que no pueda ser razonablemente justificado por él". Por su parte, el art. 20 de la Convención de Naciones Unidas contra la Corrupción caracteriza el enriquecimiento ilícito de la misma forma, intercalando, además, la oración "cuando se cometa intencionalmente". Esto último es una incongruencia que puede deberse, quizás, a las transacciones que se realizan en el proceso de negociación de un tratado. En efecto, tal como sucede con los conflictos de intereses, el enriquecimiento ilícito no es una conducta, por lo cual no puede cometerse o dejar de cometerse intencionalmente o de otro modo. Se trata más bien de una situación de incremento patrimonial que evidencia un origen ilícito, el cual puede haber consistido en uno o varios de los actos de corrupción señalados en el párrafo anterior. Las objeciones que desde el punto de vista de la teoría penal se han formulado respecto de tal tipificación del enriquecimiento ilícito (sobre lo que no corresponde abundar aquí) explica las frases condicionales con que comienza el artículo IX de la Convención Americana.

5 Chile depositó el instrumento de ratificación de la Convención Interamericana Contra la Corrupción el 27 de octubre de 1998; ratificó la Convención de la OCDE el 18 de abril de 2001 y la Convención de las Naciones Unidas el 13 de septiembre de 2006 . 
disposición de los Estados para cooperar respecto de crímenes de terrorismo (e, indirectamente, también respecto del fenómeno de la corrupción, cuyos beneficios ilícitos suelen ser, tal como los fondos de financiación del terrorismo, objeto de blanqueo de dineros, de creación de cuentas bancarias simuladas y otros artificios semejantes).

La Convención de la OCDE, acotada al tema específico del soborno internacional, no trata los conflictos de intereses.

La Convención Interamericana contiene una referencia a ellos en su artículo III.1, el cual establece que las medidas para prevenir la corrupción respecto de los funcionarios públicos tendrán, entre otros fines, los de evitar tales conflictos.

La Convención de las Naciones Unidas incluye cuatro menciones a los conflictos de intereses: el artículo 7, sobre el Sector Público, contiene, en su número 4, el compromiso general de los Estados Partes de procurar prevenir dichos conflictos. El artículo 8, sobre código de conducta para los funcionarios públicos, se refiere al establecimiento de sistemas de declaración de bienes, intereses y regalos por parte de éstos, con miras a precaver posibles conflictos de intereses. El artículo 12, sobre el Sector Privado, contiene, en su número 2.b., una mención general a que las normas que regulan la actividad privada deben apuntar, entre otros fines, a la prevención de conflictos de intereses. El mismo artículo, en su número 2.e., establece las restricciones que los Estados pueden considerar imponer para prevenir la posibilidad de la llamada "puerta giratoria", conducta a la cual se alude más adelante.

\section{Ausencia de una definición de conflicto de intereses}

Ninguna de las convenciones ya mencionadas se ocupa de definir o entregar un concepto de conflictos de intereses.

La "Guía sobre el Manejo de Conflictos de Intereses en el Sector Público y Experiencias Internacionales" de la OCDE distingue los siguientes tipos de conflictos de intereses ${ }^{6}$ :

a. Conflicto real. Existe un inaceptable conflicto de hecho entre los intereses individuales o privados del funcionario público y sus obligaciones públicas.

b. Conflicto aparente. Se refiere a la situación en que existe un interés personal que no necesariamente influiría en el funcionario público pero que podría dar lugar a que otros consideren que puede influir en el cumplimiento de sus deberes.

c. Conflicto potencial. Alude al caso en el que un funcionario público tiene un interés privado que puede convertirse en un conflicto de interés en el futuro, por ejemplo, si un familiar trabaja en la misma organización y es promovido por el funcionario, quien es su superior.

Los términos de esta categorización no son suficientemente claros. Los conflictos de intereses, a mi parecer, deben conceptualizarse como la existencia de situaciones de riesgo objetivo para los intereses públicos o los intereses de determinado colectivo porque una persona (funcionario público o agente privado) que se encuentra sometida al deber fiduciario de velar por tales intereses, mantiene, a la vez, cargos, intereses o relaciones de carácter privado (excepcionalmente, también de carácter público) que le generan el incentivo de favorecer éstos en desmedro o por encima de aquellos.

6 Los párrafos que siguen se tomaron de "Minuta Conflictos de Intereses", documento inédito de Chile Transparente. 
Puede haber una situación de conflicto de intereses que nunca redunde en un hecho ilícito, sea por la rectitud de la persona involucrada o por falta de ocasión. Si la ley y, en ausencia de ésta, solamente la moral pública, reprueban la existencia de tales situaciones, es porque entrañan un peligro para los intereses públicos o colectivos. Cuando en la práctica ellas Ilegan a comportar una efectiva vulneración de los mismos, se habrá incurrido, por parte de la persona sujeta al deber fiduciario respectivo, en una responsabilidad penal, administrativa y/o civil, si la ley contempla las sanciones del caso, o en un reproche ético, si no las establece.

Una situación objetiva de riesgo para determinados valores públicos se halla también en la raíz de las normas sobre incompatibilidades que suelen contenerse en las Constituciones políticas de diversos Estados ${ }^{7}$. El sentido de tales normas, las cuales prohíben postular a determinados cargos de elección popular a quienes detentan ciertas magistraturas públicas o posiciones de dirigencia en organizaciones sindicales o sociales, es asegurar que la separación, independencia y mutua fiscalización de los poderes del Estado sea efectiva, o bien que los vínculos de una persona con una determinada organización privada no interfieran con su obligación de velar solamente por el interés público, si resultare elegida.

Tratándose de incompatibilidades, las situaciones de conflictos de intereses no llegan, por lo general, a producirse, pues las normas legales no permiten que se acceda simultáneamente a cargos incompatibles. En el caso de conflictos entre una función fiduciaria (estatal o privada) y otros intereses privados (excepcionalmente, también públicos), la tendencia contemporánea es precisamente prevenirlos o regularlos.

Dependiendo de distintos factores, no siempre la ley o las normas de moral pública exigen que la persona sobre la que pesa un deber fiduciario se desprenda de los intereses que entran en conflicto con la independencia, imparcialidad y apego a la legalidad con que debe cumplir sus funciones. En algunas ocasiones se requiere sólo que declare abiertamente la situación objetiva de conflicto o bien que se abstenga de tomar determinadas decisiones.

\section{6. ¿Corrupción en el sector privado?}

Abundan las definiciones de corrupción ${ }^{8}$. Algunas se basan en el interés público comprometido, otras en el debido funcionamiento del mercado, unas terceras en los deberes propios de la función pública.

El criterio predominante es el de caracterizar la corrupción como un abuso de la función pública para beneficio privado. Esta posición reconoce que ciertas conductas que pueden conceptualizarse como corruptas requieren también de la participación de agentes privados (el soborno, por ejemplo). Sin embargo, se presupone la intervención de un funcionario público como condición sine qua non.

Me parece que hablar de la posibilidad de "corrupción" como un fenómeno que también puede darse en el sector privado, en lugar de referirse a ciertas conductas ilícitas dentro de este ámbito como fraudes o de otro modo que refleje un reproche legal, es una cuestión básicamente convencional y semántica. Seria ingenuo, sin embargo, desconocer las connotaciones ideológicas que conlleva la aceptación o rechazo a que se mencione la palabra corrupción, cargada como ha llegado a estar de ilegitimidad, en relación con actos entre agentes privados en los que no interviene un funcionario público. De hecho, en el debate público que ha tenido lugar en Chile

7 En la versión actualizada de la Constitución de Chile de 1980, ver los artículos 57 a 59.

8 Consultar "definitions of corruption" en googlescholar.com 
sobre conflictos de intereses desde el año 2010, diversos personeros involucrados han sostenido que en su caso no hay ni puede haber tales conflictos porque siempre han actuado correctamente $^{9}$. Ello hace evidente que ignoran o soslayan que los conflictos de intereses no son hechos, sino situaciones objetivas, independientemente de la calidad moral o de otro tipo de consideraciones respecto de las personas involucradas.

A mi parecer, corrupción significa el incumplimiento de un deber fiduciario, para beneficio propio o de terceros, por parte de alguien en quien la ciudadanía o un determinado colectivo han depositado confianza, entregándole facultades y poderes bajo el supuesto de que serán empleados ecuánimemente y con apego a la ley, en resguardo de los intereses públicos o colectivos del caso $^{10}$. Así, considero apropiado, por ejemplo, caracterizar como acto de corrupción el uso abusivo de información privilegiada por parte de un directivo de la Administradora de Fondos de Pensiones (AFP) o de una sociedad anónima, o bien de un agente de la bolsa de valores. En tales casos el orden público económico se ve afectado y no solamente los intereses de los accionistas o de los demás agentes del mercado.

La Convención de la OCDE, enfocada específicamente en combatir el soborno internacional, naturalmente se refiere a actores privados, pues tal delito presupone su participación, pero dentro del contexto de una conducta que necesariamente requiere también de la intervención de un funcionario público.

Entre los instrumentos de carácter general, la Convención Interamericana contra la Corrupción, de 1996, no alude al sector privado. De hecho, su artículo II establece que los propósitos de la Convención son:

1. Promover y fortalecer el desarrollo, por cada uno de los Estados Partes, [énfasis añadido] de los mecanismos necesarios para prevenir, detectar, sancionar y erradicar la corrupción; y

2. Promover, facilitar y regular la cooperación entre los Estados Partes a fin de asegurar la eficacia de las medidas y acciones para prevenir, detectar, sancionar y erradicar los actos de corrupción en el ejercicio de las funciones públicas [énfasis añadido] y los actos de corrupción específicamente vinculados con tal ejercicio.

En cambio, el principal instrumento internacional de tipo general, la Convención de las Naciones Unidas contra la Corrupción, de 2003, indica ya en su Prefacio que se ocupa tanto de la corrupción en el sector público como en el privado. Sobre esto último, en el articulado de dicha Convención destacan el artículo 12, que contiene detalladas normas sobre prevención de la corrupción en el sector privado; el artículo 21, sobre soborno en el sector privado; el artículo 22, sobre malversación o peculado de bienes en el sector privado; y el artículo 23, sobre blanqueo de capitales, que se aplica indistintamente a funcionarios públicos o agentes privados.

El lenguaje de los artículos 22 y 23 indica que el legislador tuvo en mente el concepto de trasgresión de deberes fiduciarios como elemento definitorio de la corrupción.

9 Por ejemplo, el Subsecretario de Deportes del gobierno del Presidente Piñera, Gabriel Ruiz-Tagle, declaró a Radio Cooperativa, el 10 de marzo de 2010, "El conflicto de intereses... tiene que ver con la conducta que uno observe en el ejercicio del cargo. Llevo 35 años trabajando y nunca he tenido algún cargo en mi contra por haber hecho algo indebido". Ver: http://www.radiocooperativa.cl/gabriel-ruiz-tagle--en-chiledeportes-no-habra-conflictos-de-interes/ prontus_nots/2010-03-10/140057.html

10 Sobre el elemento fiduciario como componente esencial del concepto de conflictos de intereses, en el libro Conflict of Interest in the Professions, editado por Michael Davis y Andrew Stark, Oxford University Press, 2001, se lee en la pág. 315: "El uso original [de la frase conflictos de intereses] apunta a relaciones de confianza en las cuales un agente fiduciario tiene o adquiere intereses pecuniarios o personales que conspiran en contra del cumplimiento de sus deberes para con sus clientes, empleadores o el público en general" (mi traducción). 


\section{Fundamentación democrática de la regulación de conflictos de intereses}

A la luz de todo lo señalado anteriormente, se desprende que la fundamentación de la regulación legal de los conflictos de intereses se apoya en los siguientes postulados propios de las sociedades democráticas modernas:

a. La legitimidad de las autoridades públicas descansa en la voluntad soberana.

b. Los cargos de autoridad están establecidos con los siguientes fines: ejercer el poder público al servicio de los objetivos democráticos; cumplir la voluntad originaria o derivada del pueblo soberano; legislar y hacer cumplir las leyes; garantizar los derechos fundamentales de las personas y promover el bien común. Por tanto, los cargos públicos son impersonales, se hallan sujetos a distintas formas de recíproca fiscalización institucional y al control ciudadano.

c. Las políticas públicas sobre el ordenamiento económico, incluyendo los sistemas y reglas respecto de intermediación financiera, determinados servicios de utilidad pública y los intereses de consumidores y usuarios, pueden hacer aconsejable que algunas actividades de utilidad general queden entregadas a agentes privados, bajo debidas regulaciones.

d. Debe prevenirse, evitarse o remediarse toda situación que atente contra el logro de los antedichos fines. Ello implica: (i) la prohibición (y sanción) de conductas que dañan el patrimonio público, la fe pública o, en general, el principio de probidad pública y de responsabilidad fiduciaria; (ii) la prohibición o regulación de ciertas conductas o situaciones, independientemente de si se produce o no daño a intereses públicos o colectivos, porque entrañan, objetivamente, una amenaza de daño de los mismos (es el caso de la regulación de los conflictos de intereses).

\section{Actos de corrupción e instituciones preventivas vinculadas a los conflictos de intereses}

Las situaciones de conflictos de intereses no debidamente prevenidas o resueltas no resultarán necesariamente en daños a intereses públicos o colectivos por parte de las personas involucradas. Cuando sí tienen como efecto tales perjuicios, las conductas dañosas suelen ser alguna o algunas de las siguientes:

a. Incumplimiento de un deber. En algunos casos pesa sobre un funcionario público o sobre un actor privado ${ }^{11}$, el deber legal o ético de declarar abiertamente una situación de conflictos de intereses, de modo que los todos puedan saber las circunstancias en las que toma una decisión dada, o bien de abstenerse directamente de tomar decisión alguna sobre la materia. Un caso característico seria el de un parlamentario llamado a votar sobre un proyecto de ley acerca de un sector de la economía en el cual tiene intereses.

b. El enriquecimiento ilícito ${ }^{12}$. Como ya ha quedado dicho ${ }^{13}$, el enriquecimiento ilícito puede ser el resultado de una o más conductas ilegales, incluyendo, entre otras, el soborno, la extorsión y la apropiación de bienes o fondos públicos. Si bien no es necesario que existan situaciones de conflictos de intereses para que se dé la hipótesis de enriquecimiento ilícito, suele ser el caso que las hay, en particular tratándose del favoritismo ilícito por parte de una autoridad pública, con miras a beneficiar a parientes, amigos o aliados, o bien de valerse de ellos como testaferros de sus propios intereses.

11 Ver en la última página referencia al artículo 29 del Código de Ética Profesional de los Abogados y nota al pie 31.

12 Para la definición normativa de enriquecimiento ilícito ver nota al pie 4.

13 Ídem. 
c. Uso abusivo de información privilegiada. Esta conducta consiste en aprovechar la información que se posee en razón de una función fiduciaria, pública o privada, para obtener beneficios que no se habrían conseguido o bien no en la misma cuantía, si se hubiera observado la obligación de guardar reserva hasta que todos los agentes potencialmente interesados pudieran acceder, simultáneamente y en igualdad de condiciones, a dicha información. Esta conducta tampoco requiere en cada caso de una situación de conflictos de intereses, pero ésta se da con mucha frecuencia en tales circunstancias, especialmente si se trata de un uso abusivo de información privilegiada en el sector privado.

d. Delitos relacionados con la administración de justicia. Las reglas procesales sobre inhabilitaciones y recusaciones, entre otras, procuran regular potenciales conflictos de esa naturaleza. Sin embargo, éstos no siempre se hacen patentes o no son descubiertos por las partes interesadas en prevenirlos, y no siempre el funcionario de justicia respectivo se inhibe de actuar.

En cuanto a las medidas tendientes a prevenir los actos de corrupción, las siguientes guardan una estrecha relación con las situaciones de conflictos de intereses:

a. Declaración de bienes e intereses ${ }^{14}$. Los estándares normativos internacionales y de muchas legislaciones nacionales determinan la conveniencia u obligación de que ciertos funcionarios públicos hagan una declaración (normalmente jurada o solemne) de bienes e intereses, incluyendo sus relaciones con sociedades y organizaciones, al momento de asumir sus funciones y que actualicen periódicamente tal declaración. De este modo se busca transparentar, anticipadamente, posibles situaciones de conflictos de intereses. Otro propósito de esta medida es el de determinar la situación patrimonial del funcionario al momento de asumir sus responsabilidades públicas, lo que puede permitir compararla con la situación del mismo funcionario más tarde o al momento de su cesación en el cargo, con miras a establecer un posible enriquecimiento ilícito.

b. El fideicomiso ciego. Tratándose de las más altas autoridades del Estado, que por su posición están Ilamadas a tomar decisiones respecto de un muy amplio rango de materias, por lo cual las situaciones de conflictos de intereses son potencialmente múltiples e indeterminables, se suele invocar la necesidad de que entreguen su patrimonio a la administración de un agente profesional, bajo prohibición de recibir información sobre cómo se está administrando o qué inversiones se han realizado o se intenta realizar. Esta institución se encuentra en la legislación de ciertos países y se denomina blind trust o fideicomiso ciego.

c. La llamada "puerta giratoria" o revolving door. Esta expresión no se refiere, como ha Ilegado a ser habitual en la prensa chilena, a la situación de personas que delinquen, obtienen prontamente la libertad y vuelven a delinquir. Alude, en cambio, al hecho de que funcionarios públicos que legislan sobre una determinada área de la economía o la regulan, suelen pasar, una vez dejado el servicio público, a trabajar para empresas que operan dentro de la misma área, como lobistas, ejecutivos o miembros del directorio; y se refiere también a la situación inversa, esto es la de lobistas o ejecutivos de empresas que pasan a ocupar un cargo en una agencia estatal Ilamada a supervisar o regular el sector económico propio de tales empresas.

14 La Ley 18.575, de 5 de diciembre de 1986, Orgánica General de Bases de la Administración del Estado, estableció para las autoridades que ejercen una función pública la obligación de hacer una declaración jurada de intereses. La Ley 20.088, de 5 de enero de 2006, la modificó, agregando la obligación de realizar una declaración jurada de patrimonio, con lo que vino a darse cumplimiento a una recomendación que ya formulara la Comisión Nacional de Ética Pública, en 1995. 
La expresión revolving door se popularizó en los Estados Unidos hace unos treinta años atrás, a propósito de una práctica común entre funcionarios ejecutivos del departamento de adquisiciones del Pentágono, el ministerio de defensa ese país, quienes jubilaban tempranamente y eran prontamente contratados por la industria de armamentos con las cuales debían tratar, supuestamente velando por los intereses del Estado, mientras servían en la función pública.

Respecto de este problema se presenta una tensión entre, por una parte, la libertad de trabajo y la necesidad del Estado de poder atraer a la función pública a profesionales competentes y, por otra, el imperativo de resguardar los intereses públicos, los cuales quedan objetivamente sujetos a una situación de riesgo si el funcionario público anticipa que los agentes privados a quienes debe regular pueden ser sus empleadores el día de mañana. Las soluciones que se han adoptado en diversos países suelen consistir en imponer al funcionario público que se encuentre en la situación del caso, un período de espera luego de dejar su cargo y antes de ingresar a trabajar para el sector privado dentro del mismo rubro que le tocaba regular. Esta limitación va a veces acompañada de una remuneración o compensación por las restricciones que implica.

Con estos antecedentes se comprende el tenor del artículo 12 de la Convención de las Naciones Unidas contra la Corrupción, que establece entre las medidas para evitar la corrupción del sector privado la siguiente:

5. Prevenir los conflictos de intereses, imponiendo restricciones apropiadas, durante un período razonable, a las actividades profesionales de ex funcionarios públicos o a la contratación de funcionarios públicos en el sector privado tras su renuncia o jubilación cuando esas actividades o esa contratación estén directamente relacionadas con las funciones desempeñadas o supervisadas por esos funcionarios públicos durante su permanencia en el cargo;

\section{Normas e iniciativas del Estado y del sector privado en Chile}

Sin procurar hacer una reseña exhaustiva, lo que excedería los límites del presente artículo, se consignan a continuación las principales normas e iniciativas que ha impulsado el Estado de Chile o han sido emprendidas por el sector privado del país en materia de anticorrupción en general y de conflictos de intereses en particular.

En las últimas dos décadas, período que coincide, aproximadamente, con la emergencia y consolidación internacional del campo de la probidad, la transparencia pública y el combate a la corrupción, se han adoptado en Chile distintas iniciativas y normas, generalmente concentradas alrededor de cuatro "momentos políticos"15.

El primero de ellos tuvo lugar en abril de 1994, durante el gobierno del Presidente Eduardo Frei Ruiz-Tagle y consistió en la creación de una Comisión Nacional de Ética Pública, compuesta por personas de distintas persuasiones políticas. Esta comisión entregó su informe en el año 1995. Su Secretario Ejecutivo, Alejandro Ferreiro, integró luego el equipo negociador del Estado chileno de la Convención Interamericana Contra la Corrupción, de 1996 que, como queda dicho, Chile ha ratificado ${ }^{16}$. En años posteriores se cumplió con algunas de las 41 recomendaciones de esta

\footnotetext{
15 Para un detallado recuento de estos "momentos" ver, MUÑOZ, Alex, Transición a la Democracia, Políticas de Probidad y Mecanismos Internacionales de Protección de Derechos Humanos. El Caso de Chile. En: ZALAQUETT, José y MUÑOZ, Alex (eds.) Transparencia y Probidad Pública. Estudios de Caso en América Latina, Centro de Derechos Humanos, Facultad de Derecho de la Universidad de Chile, 2008, pp. 113-129.

16 Ver nota al pie 5 .
} 
Comisión de Ética Pública, a saber ${ }^{17}$ : (i) se incorporaron los principios de probidad y transparencia a la Ley Orgánica Constitucional de Bases Generales de la Administración del Estado ${ }^{18}$; (ii) se creó el portal ChileCompra, un sitio de internet relativo a las adquisiciones públicas ${ }^{19}$; (iii) se constituyó el Consejo de Alta Dirección Pública ${ }^{20}$ con el fin de reducir los cargos estatales de nombramiento de exclusiva confianza de la o el Presidente de la República y recomendar, luego de concurso, candidatos debidamente calificados para la mayoría de los cargos que acostumbraban a designarse por la mera voluntad del mandatario; (iv) se tipificaron nuevos delitos, como el tráfico de influencia y el uso indebido de información privilegiada y se reformo la tipificación de otros ${ }^{21}$.

En 2003, durante la administración del presidente Ricardo Lagos, luego de algunos escándalos cubiertos por la prensa nacional, especialmente el que fue conocido como MOP-GATE, se formó una Comisión para el Fortalecimiento de la Transparencia y la Probidad Pública, con apoyo de la oposición política. Esta Comisión propuso 49 medidas que formaban la Ilamada "Agenda PolíticoLegislativa para la Modernización del Estado, la Transparencia y la Promoción del Crecimiento". En el tiempo posterior al informe de esta Comisión se promulgó la ley de financiamiento de la política $^{22}$ (cuya eficacia es muy cuestionable), se perfeccionó el sistema de ChileCompras y se activaron algunas medidas propuestas por la Comisión de Ética Pública de 1994 que habían quedado rezagadas ${ }^{23}$.

La reforma constitucional del 2005, introducida por la Ley 20.050, incorporó un artículo $8^{\circ}$ a la Carta Fundamental que estableció los principios de probidad y transparencia de la función pública y su obligatoriedad para todos los órganos del Estado ${ }^{24}$.

En 2006, durante la administración de la Presidenta Michelle Bachelet y luego del escándalo de corrupción de Chiledeportes, se formó un grupo de trabajo con la misión de proponer a la Presidenta distintas iniciativas para reforzar la probidad pública ${ }^{25}$. El grupo recomendó diversas medidas. Luego, el gobierno nombró al abogado Rafael Blanco para que coordinara su seguimiento.

De las recomendaciones de este grupo cabe destacar dos que se tradujeron en leyes de la República: (i) la protección al funcionario público que denuncia irregularidades y faltas al principio de probidad $^{26}$. (ii) El establecimiento legal del acceso a información pública y la creación de un Consejo Para la Transparencia, órgano estatal autónomo encargado de promover y resguardar los

17 La siguiente enumeración está tomada de la obra citada en la nota al pie 11, pp. 117 y 118 . A ello debe agregarse que este Informe es de 1995.

18 Ley de Probidad 19.653, promulgada en diciembre de 1999.

19 Organismo creado por la Ley 19.886, de 30 de julio de 2003.

20 Creado por Ley 19.882, de 11 de junio de 2003.

21 Para un útil esquema sobre tipificación de actos de corrupción en la ley chilena ver Probidad Administrativa y Corrupción en el Código Penal Chileno, nota del profesor Jaime Náquira, en http://www.cde.cl/wps/wcm/connect/71af5f004fbf6f4 2b5f4bf46ce4e7365/16.pdf?MOD=AJPERES

22 Ley 19.884, del 5 de agosto de 2003, complementada o modificada por la leyes 19.963 y 19.964 , ambas del 26 de agosto de 2004; y por la Ley 20.053 del 6 de septiembre de 2005.

23 MUÑOZ, Alex, op.cit. p. 119.

24 Artículo $8^{\circ}$ de la Constitución Política de Chile: "El ejercicio de las funciones públicas obliga a sus titulares a dar estricto cumplimiento al principio de probidad en todas sus actuaciones". "Son públicos los actos y resoluciones de los órganos del Estado, así como sus fundamentos y los procedimientos que utilicen. Sin embargo, sólo una ley de quórum calificado podrá establecer la reserva o secreto de aquéllos o de éstos, cuando la publicidad afectare el debido cumplimiento de las funciones de dichos órganos, los derechos de las personas, la seguridad de la Nación o el interés nacional".

25 En aras de la transparencia, es conveniente consignar aquí que participé en este grupo de trabajo y en la comisión mencionada anteriormente.

26 Ley núm. 20.205, de 24 de julio de 2007. 
principios y derechos consagrados por la ley ${ }^{27}$. Esta última ley y el funcionamiento del Consejo para la Transparencia han probado ser un paso muy significativo en el progreso de la agenda pública de probidad y apertura.

Paralelamente, en el Senado y luego en la Cámara de Diputados ${ }^{28}$ se adoptaron medidas para hacer más transparente su gestión y los bienes, intereses y actividades de diputados y senadores.

El cuarto y más reciente de los "momentos políticos" de que da cuenta este artículo está constituido por la primera fase del gobierno del Presidente Piñera, extendiéndose hacia atrás hasta el período de su candidatura presidencial. Durante este tiempo el presidente ha terminado por tomar acciones respecto algunos de sus principales activos e intereses ${ }^{29}$, luego de demoras y reticencias, lo que ha significado en definitiva una aceptación del principio de que deben evitarse los conflictos de intereses en la gestión pública, o por lo menos, una concesión a la fuerza social y moral de esta idea. Al momento de concluirse este artículo se anunciaba públicamente el envío por parte del gobierno de nuevas enmiendas o versiones al proyecto de ley de fideicomiso ciego que está pendiente en el Congreso Nacional ${ }^{30}$.

Por su parte, en el sector de los gremios profesionales, también se reconoce desde hace tiempo la necesidad de prevenir conflictos de intereses en el ejercicio de las profesiones. El Código de Ética Profesional de los Abogados, establece en su artículo 29 que el profesional debe revelar situaciones de conflictos de intereses al cliente que ha solicitado sus servicios para que, si éste decide insistir en contratarlo, lo haga con pleno conocimiento de tales circunstancias ${ }^{31}$. El Código de Ética Médica, de 2006 32 , regula con detalle los conflictos de intereses, en especial cuando el facultativo tenga vínculos con firmas farmacéuticas u otras empresas del rubro de salud. El Código de Ética del Colegio de Periodistas ${ }^{33}$ norma situaciones de este tipo (aunque sin utilizar la expresión conflictos de intereses) en su artículo trigésimo.

En lo que toca a los gremios y asociaciones empresariales, cabe mencionar el Comité de Regulación de la Bolsa de Comercio de Santiago ${ }^{34}$. Organismo que, a más de conocer de reclamos individuales, ha emitido recomendaciones sobre normas de conducta para los corredores de la bolsa.

En conclusión, en las últimas dos décadas Chile ha hecho progresos en materia de normas e instituciones relativas a la transparencia, probidad pública y combate a la corrupción. Tales avances, que han coincidido aproximadamente con el creciente desarrollo internacional del campo respectivo, han sido graduales, parciales y generalmente impulsados por algún escándalo o serie de escándalos de corrupción. En los últimos tres a cuatro años, y particularmente a lo largo del año 2010 que este Anuario pretende cubrir, el tema específico de los conflictos de intereses ha cobrado especial realce. Queda, sin embargo, bastante por hacer, no solamente en el plano normativo y regulatorio sino también, y quizás principalmente, en lo que toca a un mayor fortalecimiento de una cultura de transparencia y probidad en los sectores público y privado.

27 Ley núm. 20.285 de 20 de agosto de 2008, que entró en vigencia el 20 de abril de 2009.

28 Ver la sección Transparencia en el sitio web www.senado.cl y la sección Transparencia Activa en www.camara.cl.

29 Ver nota al pie 1.

30 Ver Boletín 5282-07 en http://www.bcn.cl

31 Este Código de Ética fue aprobado por el Consejo General del Colegio de Abogados el 28 de diciembre de 1948 y hecho suyo por la institución gremial sucesora de aquélla, el Colegio de Abogados A.G., en 1984.

32 Ver texto en http://www.colegiomedico.cl

33 Aprobado en el Consejo Plenario del Colegio de Periodistas el 13 de diciembre de 2008.

34 Fue creado como órgano autónomo, en virtud del artículo 46 del Estatuto de la Bolsa de Comercio de Santiago, Bolsa de Valores y su Reglamento aprobado por oficio núm. 1558 de la Superintendencia de Valores y Seguros, de 5 de febrero de 2007. 